\title{
UNDERUSE OF CORONARY REVASCULARIZATION PROCEDURES IN PATIENTS CONSIDERED APPROPRIATE CANDIDATES FOR REVASCULARIZATION
}

Harry Hemingway, M.R.C.P., Angela M. Crook, M.Sc., Gene Feder, F.R.C.G.P., Shrilla BanerJee, M.R.C.P., J. Rex Dawson, F.R.C.P., Patrick Magee, F.R.C.S., Sue Philpott, M.Sc., Julie Sanders, B.Sc., Alan Wood, F.R.C.S., AND AdAM D. TIMMIS, F.R.C.P.

\begin{abstract}
Background Ratings by an expert panel of the appropriateness of treatments may offer better guidance for clinical practice than the variable decisions of individual clinicians, yet there have been no prospective studies of clinical outcomes. We compared the clinical outcomes of patients treated medically after angiography with those of patients who underwent revascularization, within groups defined by ratings of the degree of appropriateness of revascularization in varying clinical circumstances.
\end{abstract}

Methods This was a prospective study of consecutive patients undergoing coronary angiography at three London hospitals. Before patients were recruited, a nine-member expert panel rated the appropriateness of percutaneous transluminal coronary angioplasty (PTCA) and coronary-artery bypass grafting (CABG) on a nine-point scale (with 1 denoting highly inappropriate and 9 denoting highly appropriate) for specific clinical indications. These ratings were then applied to a population of patients with coronary artery disease. However, the patients were treated without regard to the ratings. A total of 2552 patients were followed for a median of 30 months after angiography.

Results Of 908 patients with indications for which PTCA was rated appropriate (score, 7 to 9), 34 percent were treated medically; these patients were more likely to have angina at follow-up than those who underwent PTCA lodds ratio, 1.97; 95 percent confidence interval, 1.29 to 3.00). Of 1353 patients with indications for which CABG was considered appropriate, 26 percent were treated medically; they were more likely than those who underwent CABG to die or have a nonfatal myocardial infarction - the composite primary outcome (hazard ratio, 4.08; 95 percent confidence interval, 2.82 to 5.93 ) - and to have angina (odds ratio, 3.03; 95 percent confidence interval, 2.08 to 4.42). Furthermore, there was a graded relation between rating and outcome over the entire scale of appropriateness ( $P$ for linear trend $=0.002$ ).

Conclusions On the basis of the ratings of the expert panel, we identified substantial underuse of coronary revascularization among patients who were considered appropriate candidates for these procedures. Underuse was associated with adverse clinical outcomes. (N Engl J Med 2001;344:645-54.)

Copyright (c) 2001 Massachusetts Medical Society.

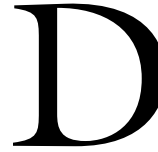
ECIDING which patients should undergo coronary revascularization remains a key challenge in the management of coronary artery disease, with individual physicians' practice patterns varying widely. ${ }^{1}$ The recommendation of revascularization is usually made by the patient's own specialist, based on an implicit judgment that the benefits of the procedure in terms of survival or decreased morbidity outweigh the risks. Expert panels' ratings of the appropriateness of revascularization in patients with a variety of typical indications, determined according to the RAND-University of California at Los Angeles (UCLA) method, make this judgment explicit, by making it possible to assign patients a score on a scale that ranges from appropriate through uncertain to inappropriate. Studies using this method have shown that overuse ${ }^{2-11}$ of invasive techniques in the management of coronary disease is uncommon, and attention has turned to the issue of underuse. ${ }^{12-16}$ Well-designed expert panels can closely reflect the views of practicing physicians, ${ }^{17}$ and methods for detecting the underuse of revascularization are highly reproducible. ${ }^{18}$

Despite reports on the ratings of a large number of expert panels ${ }^{2-11}$ on coronary revascularization, a central aspect of the validity of the appropriateness-rating method remains untested. If expert panels' judgments have clinical validity, then patients who are treated according to their ratings should have better clinical outcomes than those who are not. Furthermore, greater clinical benefits might be expected at higher levels of appropriateness. It is common for patients not to receive appropriate invasive treatment for coronary disease; 22 to 41 percent of patients for whom expert panels deem a procedure not only appropriate

From the Department of Research and Development, Kensington \& Chelsea and Westminster Health Authority (H.H., A.M.C., S.P., J.S.); the Department of Epidemiology and Public Health, University College London Medical School (H.H.); the Department of General Practice and Primary Care, St. Bartholomew's and the Royal London School of Medicine and Dentistry (G.F.); and the Cardiac Directorate, Barts and the London National Health Service Trust (S.B., J.R.D., P.M., A.W., A.D.T.) - all in London. Address reprint requests to Dr. Hemingway at the Department of Research and Development, Kensington \& Chelsea and Westminster Health Authority, 50 Eastbourne Terr., London W2 6LX, United Kingdom, or at harry.hemingway@ha.kcw-ha.nthames.nhs.uk. 
but also necessary do not undergo the procedure..$^{12-16}$ The only previous study of clinical outcomes ${ }^{12}$ found retrospectively that, among patients for whom revascularization was deemed necessary, the rate of survival was higher and there was less chest pain among those who underwent revascularization than among those who were treated medically. However, the study was limited by insufficient statistical power to separate outcomes in patients undergoing percutaneous transluminal coronary angioplasty (PTCA) from those in patients undergoing coronary-artery bypass grafting (CABG). Previous studies of coronary revascularization have not examined clinical outcomes in relation to the entire range of ratings of appropriateness.

We undertook a prospective study of clinical outcomes, the Appropriateness of Coronary Revascularization (ACRE) study, in which prior judgments about the appropriateness of indications for revascularization, determined by an expert panel, were applied to a population-based cohort of patients with coronary artery disease. The primary hypothesis was that patients who were classified as appropriate candidates for revascularization but who did not undergo the procedure would have worse outcomes than those who did undergo it, independently of other clinical characteristics.

\section{METHODS}

\section{Appropriateness Ratings}

The ACRE appropriateness ratings for PTCA and CABG were determined in 1995, before the patients were recruited, and the internal consistency, validity, and reliability of these ratings have been reported elsewhere. ${ }^{19}$ Using the RAND-UCLA Delphi method, a nine-member expert panel rated 984 mutually exclusive indications for CABG and 995 indications for PTCA. Specific indications were grouped into broad clinical presentations (examples are shown in Table 1) and were categorized according to the severity of symptoms, the number of diseased vessels, the involvement or noninvolvement of the proximal left anterior descending artery, the ejection fraction, the results on noninvasive testing for ischemia, the degree of risk posed by surgery (defined according to the method of Parsonnet et al..$^{20}$ ), and current medications. Panelists rated the appropriateness of each procedure separately for each clinical presentation, and the median of their scores was obtained.

Median scores ranged from 1 to 9 , with 1 to 3 considered to indicate that the procedure was inappropriate, 4 to 6 that its appropriateness was uncertain, and 7 to 9 that it was appropriate. Revascularization was deemed inappropriate when risks were judged to exceed benefits, of uncertain appropriateness when benefits and risks were approximately equal or when the best available evidence did not support a judgment either way, and appropriate when benefits exceeded risks by a sufficient margin to make the procedure worth performing. Each indication was defined in sufficient detail that the procedure could be considered to be equally appropriate (or inappropriate) for all patients with that indication. Examples of the panel's ratings of frequently occurring indications are presented in Table 1 .

\section{Study Population}

Before recruiting patients, we determined that 3800 patients scheduled to undergo coronary angiography would be required to allow us to detect an increase of at least 60 percent (hazard ratio, $\geqslant 1.60$ ) in the risk of the prespecified composite primary outcome (death from any cause or nonfatal myocardial infarction) among patients who had indications for which CABG was deemed appropriate but who did not undergo CABG, as compared with those who appropriately underwent CABG ( 90 percent power, two-sided $\mathrm{P}=0.05$ ). Patients were eligible for inclusion in the study if they were to undergo elective or emergency coronary angiography at any of three neighboring teaching hospitals in the City of London and

Table 1. Examples of Frequent Indications for PTCA and CABG. *

\begin{tabular}{|c|c|c|c|c|c|c|}
\hline \multirow[t]{2}{*}{ Clinical Presentation } & \multicolumn{4}{|c|}{ VARIABLES Used to DeFINE Indications } & \multicolumn{2}{|c|}{ ApPropriateness Category (Score) } \\
\hline & $\begin{array}{l}\text { SYMPTOMS, THERAPY } \\
\text { AND ECG RESULTS }\end{array}$ & $\begin{array}{c}\text { LEVEL OF } \\
\text { OPERATIVE RISK }\end{array}$ & $\begin{array}{l}\text { EJECTION } \\
\text { FRACTION }\end{array}$ & NO. OF DISEASED VESSELS & PTCA & CABG \\
\hline \multicolumn{7}{|c|}{$\%$} \\
\hline \multirow[t]{2}{*}{$\begin{array}{l}\text { Chronic stable angina, } \\
\text { CCS class I or II }\end{array}$} & $\begin{array}{l}\text { Submaximal medical therapy, } \\
\text { very positive exercise ECG }\end{array}$ & Moderate & $>35$ & $\begin{array}{l}\text { I without proximal left anterior } \\
\text { descending artery }\end{array}$ & Uncertain (4) & Inappropriate (3) \\
\hline & Any & Any & $>15$ & 3 with left main coronary artery & Inappropriate (1) & Appropriate (9) \\
\hline \multirow[t]{2}{*}{$\begin{array}{l}\text { Chronic stable angina, } \\
\text { CCS class III or IV }\end{array}$} & Submaximal medical therapy & Moderate & $>35$ & $\begin{array}{l}\text { I with proximal left anterior de- } \\
\text { scending artery }\end{array}$ & Appropriate (7) & Uncertain (6) \\
\hline & Maximal medical therapy & Low & $>35$ & $\begin{array}{l}\text { I with proximal left anterior de- } \\
\text { scending artery }\end{array}$ & Appropriate (9) & Appropriate (8) \\
\hline \multirow[t]{2}{*}{ Unstable angina } & $\begin{array}{l}\text { Asymptomatic with maximal } \\
\text { medical therapy }\end{array}$ & $\begin{array}{l}\text { Low or } \\
\text { moderate }\end{array}$ & $>35$ & $\begin{array}{l}\text { Left main coronary artery, a total } \\
\text { of } 3 \text {, or } 2 \text { with proximal left } \\
\text { anterior descending artery }\end{array}$ & Inappropriate $(3)$ & Appropriate (9) \\
\hline & $\begin{array}{l}\text { Symptoms with submaximal } \\
\text { medical therapy }\end{array}$ & Low & $>35$ & $\begin{array}{l}1 \text { or } 2 \text { without proximal left an- } \\
\text { terior descending artery }\end{array}$ & Appropriate (7) & Appropriate (7) \\
\hline \multirow[t]{2}{*}{$\begin{array}{l}\leqslant 21 \text { Days after acute } \\
\text { myocardial infarction }\end{array}$} & $\begin{array}{l}\text { Asymptomatic, very positive } \\
\text { exercise ECG }\end{array}$ & $\begin{array}{l}\text { Low or } \\
\text { moderate }\end{array}$ & $>15$ & $\begin{array}{l}2 \text { without proximal left anterior } \\
\text { descending artery }\end{array}$ & Uncertain (5) & Uncertain (5) \\
\hline & $\begin{array}{l}\text { Asymptomatic, positive exer- } \\
\text { cise ECG }\end{array}$ & Low & $>15$ & $\begin{array}{l}1 \text { or } 2 \text { with proximal left anterior } \\
\text { descending artery }\end{array}$ & Uncertain (6) & Uncertain (6) \\
\hline
\end{tabular}

*A total of 984 indications were rated for CABG and 995 indications for PTCA, of which 312 occurred in the study sample of 2552 patients with coronary artery disease. A total of 521 patients had indications that made them appropriate candidates for both CABG and PTCA. ECG denotes electrocardiogram. CCS class refers to the Canadian Cardiovascular Society classification of symptoms, ranging from I (mild) to IV (severe). The abnormalities on the exercise ECG were defined by RAND. Operative risk was measured by the method of Parsonnet et al. ${ }^{20}$ 
the East End (London Chest, St. Bartholomew's, and Royal London hospitals) between April 15, 1996, and April 14, 1997, and if they lived within the contiguous catchment areas of the five health authorities covering the City of London, East London, and Essex. There were no criteria for exclusion, and 4121 eligible patients were identified..$^{21}$ The resident population of the combined catchment area was $2,833,000$, and 89 percent of the angiography procedures performed in this population were performed at these hospitals. Approval for the study was obtained from the five local research-ethics committees, and written informed consent was obtained from all patients.

\section{Data from Clinical Records}

Eligible patients were identified on the day of their index coronary angiography through the examination of logs of admissions to wards and catheterization laboratories. Data were abstracted from case notes by trained nurses using standardized recording forms. Details were obtained on clinical presentation (as defined by RAND $^{22}$ ), Canadian Cardiovascular Society (CCS) classification ${ }^{23}$ of the functional severity of angina (ranging from class I, denoting mild angina, to class IV, denoting severe angina), current medications, presence or absence of diabetes, results on exercise electrocardiography (ECG), ${ }^{22}$ coexisting conditions, and the physician's intended treatment plan.

\section{Angiographic Data}

After angiography was performed, the angiographic findings were obtained from the written report of angiographic results found in each patient's case notes and were coded by a trained coder who was unaware of the clinical details. The severity of disease in each of the 27 coronary-artery segments defined by the Coronary Artery Surgery Study ${ }^{24}$ was coded from 1 (no disease) to 6 (occlusion), and the number of diseased vessels was calculated. In order to assess the reliability of this approach, two cardiologists who were unaware of the clinical details reviewed a random sample of 209 angiograms. There was good agreement beyond the degree expected by chance between the cardiologists and the trained coder, with weighted kappas of 0.64 and $0.63 .{ }^{25}$ Coronary artery disease, defined as stenosis of 50 percent or more of the luminal diameter in the left main coronary artery or of 70 percent or more in other arteries, was present in 2729 patients, for 2552 of whom (94 percent) there were sufficient data for us to assign a score for the appropriateness of CABG; the corresponding figure for PTCA was 2503 . These patients became the study population.

\section{Follow-up}

We identified the first revascularization procedures performed in study patients after the index coronary angiography by crosschecking a national electronic information system (the National Health Service-Wide Clearing System) and the hospitals' log books for catheterization laboratories and operating rooms, using a unique identifier, the patient's National Health Service number.

Patients were followed for the composite end point of death or nonfatal myocardial infarction until April 14, 1999, resulting in a median follow-up period of 30 months (range, 0 to 36 ). The records of the vital status of 2537 patients (99 percent) were flagged (with the unique identifier) at the central registry of the Office for National Statistics so that we would be notified of the date of death if they died. We ascertained possible cases of nonfatal myocardial infarction by searching the data base of the National Health Service-Wide Clearing System for discharges coded for coronary artery disease (codes I20 to I25 of the International Statistical Classification of Diseases and Related Health Problems, 10th Revision [ICD-10] $)^{26}$ and by means of manual searches of admissions records in the 13 hospitals that referred patients for angiography. Acute myocardial infarction was defined according to the criteria of the World Health Organization's Monitoring Trends and Determinants in Cardiovascular Disease (MONICA) project. ${ }^{27}$

The presence and severity of angina were assessed according to the CCS scale on the basis of data obtained from questionnaires sent to patients 12 months after revascularization or 12 months after angiography if no revascularization had been performed. Among patients who had coronary artery disease at the time of angiography and were alive 12 months later, the response rate was 76 percent (1835 of 2416). Those who responded were older $(\mathrm{P}<0.001)$ and more likely to be white $(\mathrm{P}<0.001)$ and were less likely to have undergone a previous PTCA procedure $(\mathrm{P}=0.03)$, but otherwise they did not differ significantly from those with no response in terms of the demographic and clinical characteristics in Table 2.

\section{Statistical Analysis}

The clinical outcomes of the patients who were treated medically were compared with the outcomes of those who underwent CABG or PTCA after angiography; comparisons were made separately for each type of procedure, within each category of appropriateness. Each patient's first revascularization procedure after the index angiography was analyzed. The independent effect of CABG or PTCA on outcomes was estimated with the use of Cox proportional-hazards models (for the composite primary outcome of death and nonfatal myocardial infarction) and logistic regression (for the presence or absence of angina). By design, the appropriateness method classifies patients on the basis of risk. We used multivariate adjustments of hazard ratios and odds ratios to reduce the possibility of residual confounding. Survival data were compared by means of Kaplan-Meier curves and the log-rank test. Proportions were compared by means of the chi-square statistic. Linear trends in the hazard ratio across the categories of appropriateness were assessed with the use of a likelihood-ratio test. All analyses were performed with the use of SAS software. ${ }^{28}$

\section{RESULTS}

Of the 2552 patients analyzed, 908 had indications for which PTCA was deemed appropriate and 1353 had indications for which CABG was deemed appropriate (Table 2 ). There were 521 patients who were deemed appropriate candidates for both PTCA and CABG. PTCA procedures were performed in 34 (6 percent) of the 568 patients whom we rated as inappropriate candidates for PTCA, in 223 (22 percent) of the 1027 patients for whom we rated the appropriateness of PTCA as uncertain, and in 327 (36 percent) of the 908 patients whom we rated as appropriate candidates ( $\mathrm{P}$ for linear trend $<0.001$ ). For $\mathrm{CABG}$, the corresponding figures were 15 ( 8 percent) of 186 patients, 212 (21 percent) of 1013 patients, and 765 (57 percent) of 1353 patients ( $P$ for linear trend $<0.001)$. Of the 908 patients classified as appropriate candidates for PTCA at the time of angiography, 327 (36 percent) underwent PTCA, 273 (30 percent) underwent $\mathrm{CABG}$, and 308 (34 percent) received only medical treatment. Of the 1353 patients classified as appropriate candidates for CABG, 765 (57 percent) underwent CABG, 234 (17 percent) underwent PTCA, and 354 (26 percent) received only medical treatment. Of all the PTCA procedures, 56 percent involved stenting ( 55 percent, 56 percent, and 63 percent in the appropriate, uncertain, and inappropriate categories, respectively). Of the 308 patients whom we classified as appropriate candidates for PTCA but who received only medical treatment, the recorded intention of the physician at the time of angiography was to use medical treatment in 89 percent. The corresponding figure for CABG was 81 percent. 
Table 2. Demographic and Clinical Characteristics of Patients with InDiCATIONS AT ANGIOGRAPHY FOR Which REVASCULARIZATION WAS JUdGed Appropriate, According to Subsequent Revascularization Status.

\begin{tabular}{|c|c|c|c|c|c|}
\hline \multirow[t]{2}{*}{ Characteristic } & \multirow[t]{2}{*}{$\begin{array}{c}\text { All Patients } \\
\text { With Coronary } \\
\text { ARTERY Disease } \\
(\mathbf{N}=\mathbf{2 5 5 2})\end{array}$} & \multicolumn{2}{|c|}{$\begin{array}{l}\text { PTCA APPROPRIATE } \\
(\mathrm{N}=908)^{*}\end{array}$} & \multicolumn{2}{|c|}{$\begin{array}{l}\text { CABG APPROPRIATE } \\
(\mathrm{N}=1353) \dagger\end{array}$} \\
\hline & & $\begin{array}{l}\text { PTCA } \\
(\mathrm{N}=327)\end{array}$ & $\begin{array}{l}\text { MEDICAL } \\
\text { TREATMENT } \\
(\mathrm{N}=308)\end{array}$ & $\begin{array}{c}\text { CABG } \\
(\mathrm{N}=765)\end{array}$ & $\begin{array}{c}\text { MEDICAL } \\
\text { TREATMENT } \\
(\mathrm{N}=354)\end{array}$ \\
\hline \multicolumn{6}{|l|}{ Demographic } \\
\hline $\begin{array}{l}\text { Median age }(\mathrm{yr}) \\
\text { Female sex }(\%) \\
\text { Nonwhite race }(\%)\end{array}$ & $\begin{array}{l}62 \\
21 \\
14\end{array}$ & $\begin{array}{l}59 \\
25 \\
12\end{array}$ & $\begin{array}{l}60 \\
23 \\
17\end{array}$ & $\begin{array}{l}63 \\
19 \\
14\end{array}$ & $\begin{array}{l}63 \\
18 \\
20 \ddagger\end{array}$ \\
\hline \multicolumn{6}{|l|}{ Clinical } \\
\hline $\begin{array}{l}\text { Current medication (\%) } \\
\text { Aspirin } \\
\text { Beta-blocker } \\
\text { Calcium antagonist } \\
\text { ACE inhibitor } \\
\text { Nitrate } \\
\text { Statin }\end{array}$ & $\begin{array}{l}80 \\
48 \\
53 \\
24 \\
65 \\
22 \\
16\end{array}$ & $\begin{array}{l}86 \\
57 \\
55 \\
21 \\
73 \\
21 \\
11\end{array}$ & $\begin{array}{l}82 \\
52 \\
60 \\
25 \\
70 \\
25 \\
17 t\end{array}$ & $\begin{array}{l}81 \\
53 \\
58 \\
21 \\
70 \\
25 \\
15\end{array}$ & $\begin{array}{l}81 \\
42 \$ \\
58 \\
25 \\
69 \\
23 \\
21+\end{array}$ \\
\hline \multicolumn{6}{|l|}{ Severity of angina (\%) } \\
\hline $\begin{array}{l}\text { CCS class I or II } \\
\text { CCS class III or IV } \\
\text { Previous myocardial infarction (\%) } \\
\text { Abnormal exercise ECG }(\%)\end{array}$ & $\begin{array}{l}48 \\
52 \\
51 \\
80\end{array}$ & $\begin{array}{l}37 \\
63 \\
53 \\
86\end{array}$ & $\begin{array}{l}47 \\
53 \ddagger \\
58 \\
87\end{array}$ & $\begin{array}{l}41 \\
59 \\
44 \\
89\end{array}$ & $\begin{array}{l}45 \\
55 \\
52 \ddagger \\
84\end{array}$ \\
\hline \multicolumn{6}{|l|}{ Angiographic findings (\%) } \\
\hline $\begin{array}{l}1 \text { Diseased vessel } \\
2 \text { Diseased vessels }\end{array}$ & $\begin{array}{l}42 \\
29\end{array}$ & $\begin{array}{l}76 \\
24\end{array}$ & $\begin{array}{l}67 \\
33\end{array}$ & $\begin{array}{r}9 \\
24\end{array}$ & $\begin{array}{l}22 \\
32\end{array}$ \\
\hline $\begin{array}{l}3 \text { Diseased vessels or left main cor- } \\
\text { onary artery }\end{array}$ & 30 & $<1$ & $0 \ddagger$ & 67 & $46 \$$ \\
\hline Diffuse disease & 16 & 7 & $12 \ddagger$ & 20 & 23 \\
\hline Impaired left ventricular function (\%) & 30 & 16 & $25 \ddagger$ & 28 & 30 \\
\hline Heart failure (\%) & 14 & 7 & $15 \$$ & 11 & $16 \ddagger$ \\
\hline Previous PTCA or stenting (\%) & 8 & 16 & $10 \ddagger$ & 5 & 7 \\
\hline Previous CABG (\%) & 10 & 6 & $19 \$$ & 5 & $19 \$$ \\
\hline \multicolumn{6}{|l|}{ Operative risk (Parsonnet score) $\|$} \\
\hline $\begin{array}{l}\text { Median } \\
\text { Interquartile range }\end{array}$ & $\begin{array}{c}6 \\
3-10\end{array}$ & $\begin{array}{c}4 \\
1-7\end{array}$ & $\begin{array}{c}5 \\
3-8 \ddagger\end{array}$ & $\begin{array}{c}6 \\
3-10\end{array}$ & $\begin{array}{c}6 \\
3-11\end{array}$ \\
\hline \multicolumn{6}{|l|}{ Coexisting condition (\%) } \\
\hline Stroke or peripheral arterial disease & 8 & 5 & 8 & 9 & 11 \\
\hline Noncardiovascular condition & 37 & 37 & 40 & 38 & 40 \\
\hline
\end{tabular}

* Of these, 635 underwent PTCA or medical treatment; the remaining 273 underwent CABG. †Of these, 1119 underwent CABG or medical treatment; the remaining 234 underwent PTCA. $\ddagger \mathrm{P}<0.05$ for the comparison with the subgroup that received PTCA or CABG. $\$ \mathrm{P}<0.01$ for the comparison with the subgroup that received PTCA or CABG. IACE denotes angiotensin-converting enzyme.

Operative risk was measured according to the method of Parsonnet et al. ${ }^{20}$ RAND defined scores lower than 9 as low risk, scores of 9 to 18 as moderate risk, and scores higher than 18 as high risk.

Among patients for whom PTCA was rated appropriate, stepwise logistic-regression analysis of all the demographic and clinical variables listed in Table 2 identified previous $\mathrm{CABG}$, heart failure, and the presence of disease in two vessels as independent predictors of which patients would receive only medical treatment rather than undergo PTCA. Among patients classified as appropriate candidates for CABG, stepwise logistic-regression analysis identified previous CABG, the presence of disease in fewer than three vessels or its absence in the left main coronary artery, a lower CCS angina class, nonuse of beta-blockers, diabetes, and nonwhite race as independent predictors of which patients would receive only medical treatment.

Tables 3, 4, and 5 show the relations among the clinical outcomes, the appropriateness classifications, and whether or not patients underwent revascularization. The results have been adjusted for age, sex, and 12 characteristics for which there were signifi- 
Table 3. Presence of Angina at 12 Months of Follow-up, According to Treatment Received and Appropriateness Category.*

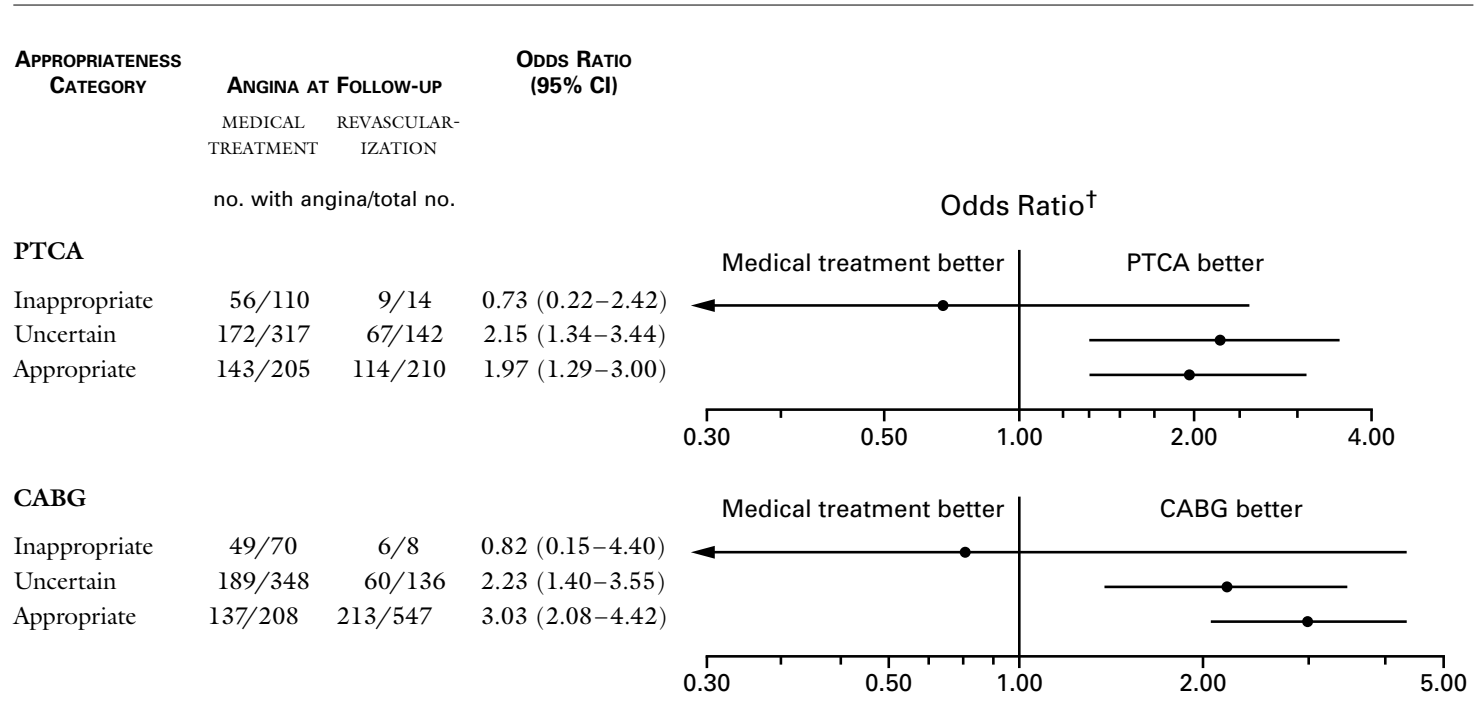

* The odds ratios compare the odds of having angina at follow-up for patients treated medically with the odds for patients who underwent PTCA or CABG. For patients with indications rated appropriate or uncertain, the odds ratios have been adjusted for age, sex, race, use or nonuse of beta-blockers, presence or absence of diabetes, history with respect to myocardial infarction, Canadian Cardiovascular Society angina class, number of diseased vessels, presence or absence of diffuse disease, presence or absence of impaired left ventricular function, presence or absence of heart failure, history with respect to revascularization, and Parsonnet score (which measures operative risk). For patients with indications rated inappropriate, the odds ratios have been adjusted for age. CI denotes confidence interval.

†Odds ratios are indicated by the solid circles (and their 95 percent confidence intervals by the horizontal lines) on a logarithmic scale. An odds ratio of 1.0 indicates no difference in the effects of revascularization and medical therapy with respect to angina at follow-up. Values greater than 1.0 indicate a beneficial effect of revascularization over medical treatment, and values less than 1.0 indicate a beneficial effect of medical treatment over revascularization.

cant differences between the treatment groups (Table 2 ). As compared with adjustment for age alone, the multivariate adjustment tended to have little additional effect on our estimates of hazard ratios or odds ratios. The small number of events that occurred among patients classified as inappropriate candidates for the procedures precluded multivariate adjustment in that category.

\section{Medical Treatment versus PTCA}

Among all 584 patients who underwent PTCA, 34 (6 percent) had indications rated as inappropriate for PTCA, 223 (38 percent) had indications rated as uncertain, and 327 ( 56 percent) had indications rated as appropriate. Patients whom we classified as appropriate candidates for PTCA but who received medical treatment were more likely to have angina at follow-up (odds ratio, 1.97; 95 percent confidence interval, 1.29 to 3.00) (Table 3 ) than those who received PTCA, but the two groups were equally likely to die or have a nonfatal myocardial infarction during follow-up (hazard ratio, 0.77 ; 95 percent confidence interval, 0.48 to 1.25 ) (Table 4 ).

\section{Medical Treatment versus CABG}

Among all 992 patients who underwent CABG, 15 ( 2 percent) had indications rated as inappropriate for CABG, 212 (21 percent) had indications rated as uncertain, and 765 (77 percent) had indications rated as appropriate. Patients whom we classified as appropriate candidates for CABG but who received medical treatment were more likely than those who received CABG to have angina at follow-up (odds ratio, 3.03; 95 percent confidence interval, 2.08 to 4.42 ) (Table 3 ) and to die or have a nonfatal myocardial infarction during the follow-up period (hazard ratio, 4.08; 95 percent confidence interval, 2.82 to 5.93 ) (Table 4). Patients whom we classified as appropriate candidates for CABG had a risk of death or nonfatal myocardial infarction within two years after angiography of 21 percent if they received medical treatment, as compared with 6 percent among those who underwent CABG $(\mathrm{P}<0.001$ by the log-rank test $)$ (Fig. 1). Patients for whom we considered CABG of uncertain appropriateness who received medical treatment were also more likely to have angina at followup (odds ratio, 2.23; 95 percent confidence interval, 


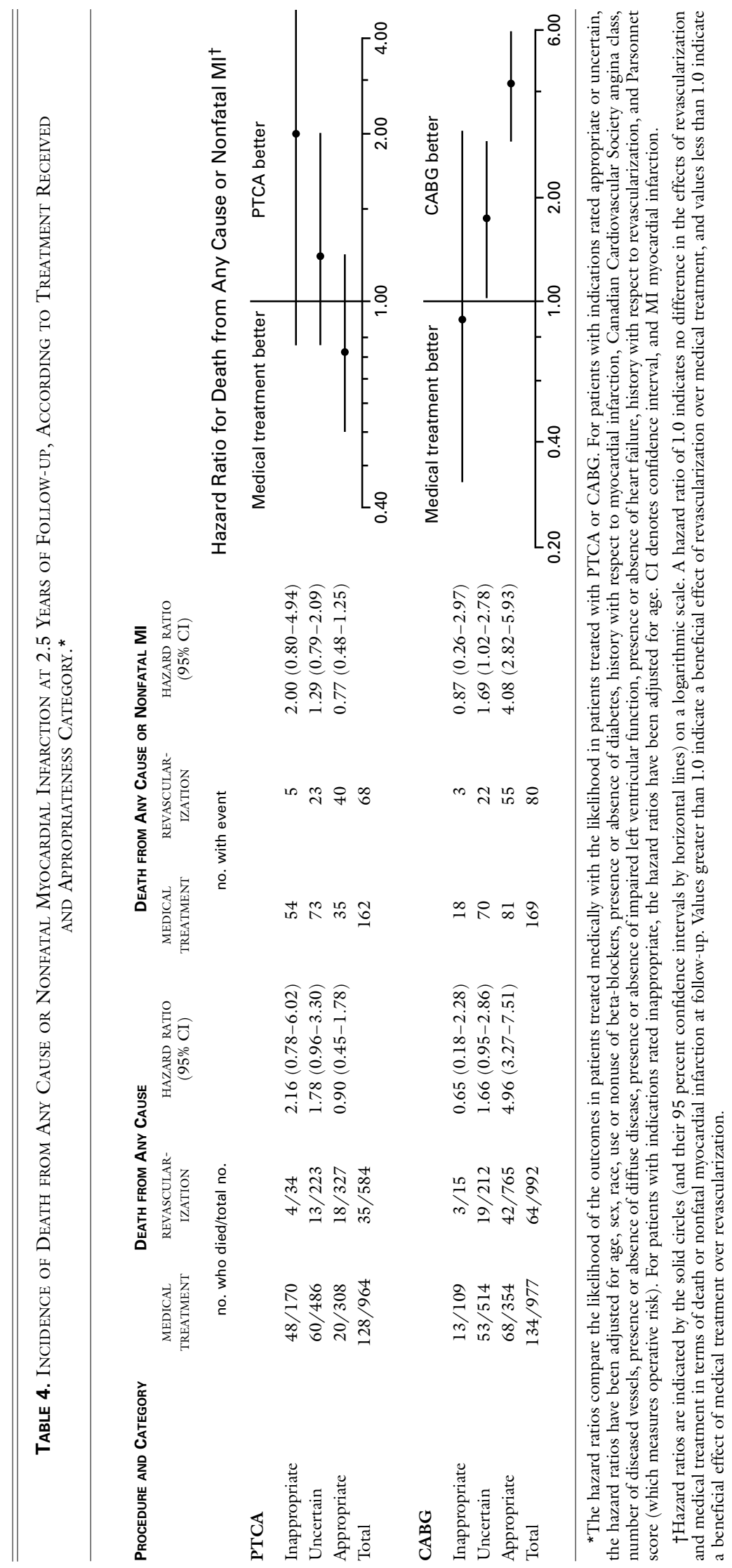

650 - N Engl J Med, Vol. 344, No. 9 • March 1, $2001 \cdot$ www.nejm.org 
Table 5. Incidence of Death from Any Cause or Nonfatal Myocardial Infarction at 2.5 Years of Follow-up, According to Receipt of Medical Treatment or CABG, within Five Categories of Appropriateness.*

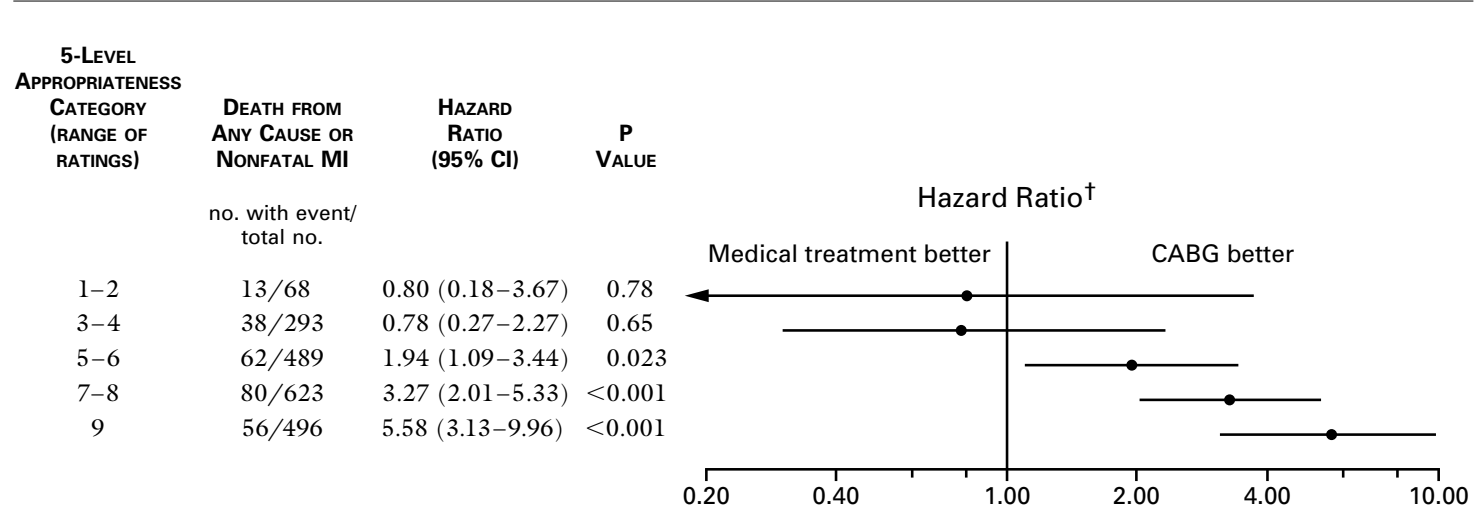

\footnotetext{
* The hazard ratios compare the likelihood of death from any cause or nonfatal myocardial infarction in patients treated medically with that in patients undergoing CABG. For patients with indications rated 3 through 9 , the hazard ratios have been adjusted for age, sex, race, use or nonuse of beta-blockers, presence or absence of diabetes, history with respect to myocardial infarction, Canadian Cardiovascular Society angina class, number of diseased vessels, presence or absence of diffuse disease, presence or absence of impaired left ventricular function, presence or absence of heart failure, history with respect to revascularization, and Parsonnet score (which measures operative risk). For patients with indications rated 1 or 2, the hazard ratios have been adjusted for age. CI denotes confidence interval, and MI myocardial infarction. In other analyses, ratings of 1 through 3 indicate the inappropriateness of revascularization, 4 through 6 uncertain appropriateness, and 7 through 9 appropriateness.

†Hazard ratios are indicated by the solid circles (and their 95 percent confidence intervals by the horizontal lines) on a logarithmic scale. A hazard ratio of 1.0 indicates no difference in the effects of CABG and medical treatment with respect to the composite end point at followup. Values greater than 1.0 indicate a beneficial effect of CABG over medical treatment, and values less than 1.0 indicate a beneficial effect of medical treatment over CABG. P for linear trend $=0.002$.
}

1.40 to 3.55$)$ and to die or have a nonfatal myocardial infarction during the follow-up period (hazard ratio, $1.69 ; 95$ percent confidence interval, 1.02 to 2.78) than those who underwent CABG.

In a stepwise proportional-hazards regression model of primary outcome, not undergoing CABG when the procedure was appropriate entered the model first; of the other variables, only impaired left ventricular function and age subsequently entered the model at a significance level of $\mathrm{P}<0.05$.

\section{Dose-Response Relations}

In order to investigate further the dose-response relation between the degree of appropriateness and the primary outcome, patients were categorized into five groups according to the ratings of appropriateness (Table 5). The effect on the primary outcome of not undergoing $\mathrm{CABG}$, as compared with undergoing $\mathrm{CABG}$, was greatest for patients whom we classified as the most appropriate candidates for CABG (those with a rating of 9 ), but it remained significant in the groups defined by ratings of 7 or 8 and 5 or $6(\mathrm{P}$ for linear trend across the five groups $=0.002)$.

\section{DISCUSSION}

In our prospective study of patients undergoing coronary angiography, medical treatment was common among patients with indications for which re- vascularization had been deemed appropriate by the ACRE expert panel. Over 2.5 years of follow-up, these medically treated patients had higher mortality and a higher prevalence of angina than patients who underwent revascularization. The findings of this prospective study provide strong evidence that ratings of appropriateness have clinical validity in measuring underuse of revascularization after angiography. Our use of the appropriateness scale enabled us to identify underuse of revascularization both among appropriate candidates and among patients with indications for which revascularization was rated as of uncertain appropriateness.

The increase in the risk of adverse outcomes associated with medical treatment was greatest among the patients whom we classified as the most appropriate candidates for CABG (patients with a rating of 9 ). However, these effects were not confined to the patients for whom CABG was rated as appropriate. Among patients to whom we assigned a rating of 5 or 6 (usually considered "uncertain"), there were also significant effects, with a hazard ratio intermediate in magnitude between that for patients rated as appropriate and that for patients rated as inappropriate. The graded relation of revascularization with clinical outcome across the five levels of appropriateness provides evidence that the judgment of the expert panel is quantified and goes beyond the identification of the 


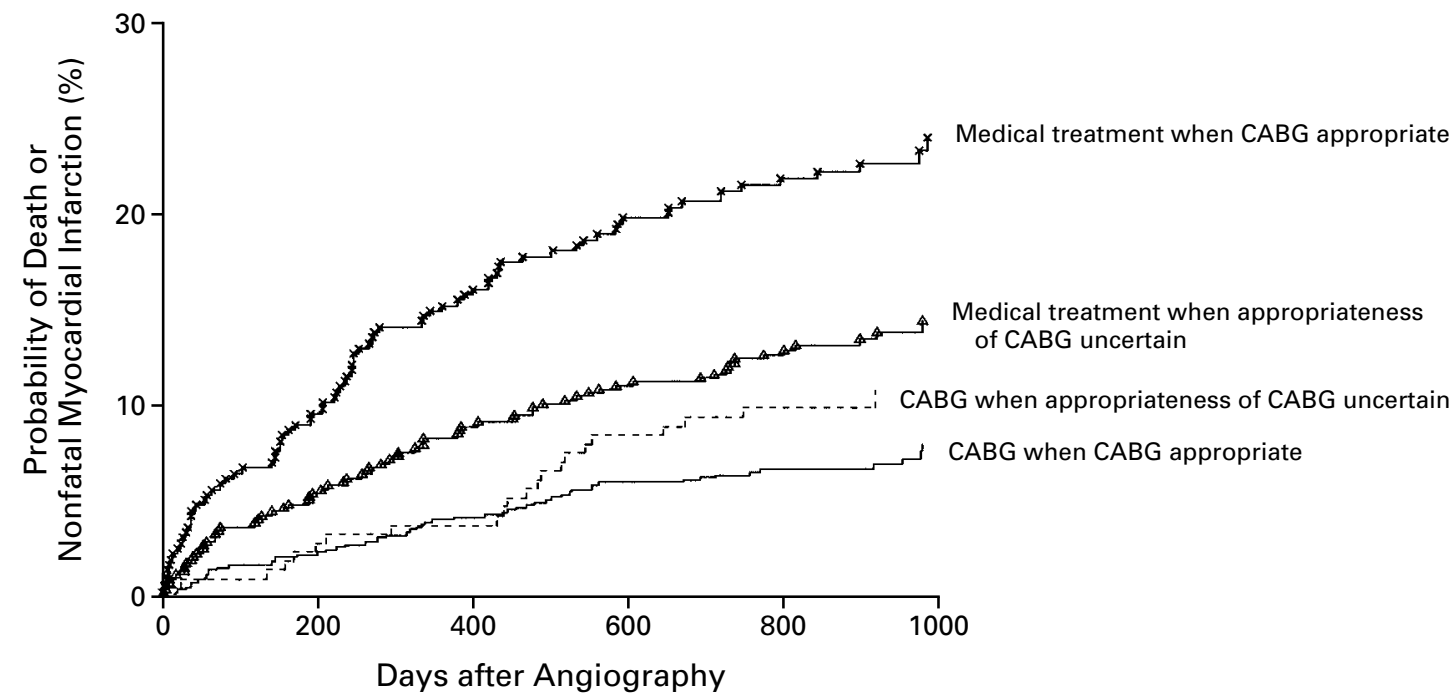

No. AT RISK

\begin{tabular}{|c|c|c|c|c|c|c|}
\hline \multicolumn{7}{|l|}{ Medical treatment } \\
\hline CABG appropriate $(x)$ & 354 & 320 & 297 & 283 & 240 & 92 \\
\hline CABG uncertain $(\Delta)$ & 514 & 486 & 468 & 457 & 366 & 118 \\
\hline \multicolumn{7}{|l|}{ CABG } \\
\hline CABG uncertain (- -) & 213 & 206 & 204 & 194 & 162 & 51 \\
\hline CABG appropriate (-) & 765 & 747 & 733 & 719 & 584 & 198 \\
\hline
\end{tabular}

Figure 1. Probability of Death from Any Cause or Nonfatal Myocardial Infarction after Angiography, According to the Appropriateness of CABG and Actual Care Received.

Among patients deemed appropriate candidates for CABG, $\mathrm{P}<0.001$ for the comparison of those treated medically with those who received CABG. Among patients deemed uncertain candidates for CABG, $P=0.037$ for the comparison of those treated medically with those who received CABG. $P$ values were determined by the log-rank test. Data for patients who were classified as inappropriate candidates for CABG are not shown because the numbers were too small for meaningful analysis.

sorts of clear-cut indications for which the evidence from randomized trials may be strongest. Previous studies have restricted the definition of underuse to the subgroup of patients for whom revascularization is judged not only appropriate but also necessary. The graded risk-benefit relation across categories of appropriateness in our study suggests that this definition is too narrow.

The better outcomes among patients for whom revascularization was deemed appropriate or uncertain were independent of a large number of clinical variables. Furthermore, they were not explained by differences in medical treatment; among the patients whom we rated as appropriate candidates for CABG we found no difference at follow-up in the use of aspirin, beta-blockers, or statins between those who underwent CABG and those who were treated medically. The effects tended to be consistent for mortality, nonfatal myocardial infarction, and angina status.

One third of the patients whom we rated as appropriate candidates for PTCA and one quarter of those whom we rated as appropriate candidates for CABG were treated medically; these rates are in line with previous estimates that 22 to 41 percent of necessary invasive procedures are not performed. ${ }^{12-16}$ As in other studies of appropriateness, matching data abstracted from clinical records with hypothetical clinical indications creates a potential source of bias. Neither the predefined indication nor the clinical record may adequately characterize the patient. However, we found a low degree of error in the angiographic records, ${ }^{25}$ and it has previously been demonstrated that there is excellent agreement between written clinical records and the results of interviews with the physicians who perform the procedures. ${ }^{29}$ Observational studies cannot exclude as explanations other unmeasured factors, and cardiologists and surgeons may choose to perform revascularization in patients who are destined to do well for other reasons. The preference of the patient is unlikely to be a major factor, since the willingness to consider revascularization is a precondition for undergoing angiography, and other studies have found refusal by the patient to be uncommon. ${ }^{13}$

We studied the underuse of revascularization in a health care system in which access is universal and 
care is free at the point of use. Constraints on costs after angiography are less likely to influence the decision to perform a revascularization procedure in such a system than may be the case in the United States. The proportion of patients with angiographically documented coronary disease who subsequently underwent revascularization was 62 percent in our study - a proportion similar to that in a large study in the United States. ${ }^{30}$ However, physicians in different countries may differ in their judgments of appropriateness ${ }^{31}$ suggesting that studies of clinical outcomes in relation to ratings of appropriateness are needed in countries where the rate of revascularization is higher than it is in the United Kingdom. ${ }^{32}$ In our study, there was good broad agreement between the categories of appropriateness defined by the expert panel and the three levels defined in the guidelines of the American Heart Association and the American College of Cardiology. ${ }^{33}$ However, the accumulation of new evidence regarding the effectiveness of revascularization demands an updating of the process of rating appropriateness.

Our findings raise a fundamental question about clinical decision making: Are the explicit, quantified judgments of an expert panel a better guide to the proper use of coronary revascularization than the variable decisions of individual clinicians? Reliance on an expert panel offers four potential advantages. First, as our study without exclusion criteria demonstrates, it is possible to assign an appropriateness rating in nearly all patients - not just the highly selected patients represented in trials. In making a decision together about whether to choose revascularization, the doctor and the patient can both identify the relevant clinical indications from the list used by the panel (which are specified in more detail than they are in existing guidelines) and match them to the panel's ratings and the associated clinical outcomes. A patient with coronary disease who is not referred for revascularization by one doctor might reasonably ask, "What would the panel say?" Second, an expert panel may be better than individual clinicians at articulating the evolving results of clinical trials and applying changing technology for use in patients seen in routine clinical practice. Third, the format of the ninemember expert panel, which we used in our study, may "average out" variations in clinical decision making among individual physicians. The use of a multidisciplinary panel of surgeons, cardiologists, and general internists may reduce the practice of cardiologists' "referring patients to themselves," which may not be optimal. ${ }^{34}$ Fourth, an expert panel is able to make "pure" clinical decisions without the constraints of cost or expediency, on the basis of an algorithm that uses a small number of salient clinical details.

In our study, the underuse of coronary revascularization after angiography was common and, particularly in the case of CABG, was associated with ad- verse clinical outcomes. The integration of explicit measures of appropriateness into routine clinical decision making may improve the quality of care.

Supported by grants from the Health Authorities of East London and the City, North Essex, Barking and Havering, and Redbridge and Waltham Forest; the North Thames National Health Service Research and Development program (RFG 258); the British Heart Foundation (PG/97216); Guidant; and Boston Scientific.

We are indebted to the patients for their participation in this research.

\section{REFERENCES}

1. Selby JV, Fireman BH, Lundstrom RJ, et al. Variation among hospitals in coronary-angiography practices and outcomes after myocardial infarction in a large health maintenance organization. N Engl J Med 1996;335: 1888-96.

2. Winslow CM, Kosecoff JB, Chassin M, Kanouse DE, Brook RH. The appropriateness of performing coronary artery bypass surgery. JAMA 1988;260:505-9.

3. Gray D, Hampton JR, Bernstein SJ, Kosecoff J, Brook RH. Audit of coronary angiography and bypass surgery. Lancet 1990;335:1317-20.

4. Hilborne LH, Leape LL, Bernstein SJ, et al. The appropriateness of use of percutaneous transluminal coronary angioplasty in New York State. JAMA 1993;269:761-5.

5. Leape LL, Hilborne LH, Park RE, et al. The appropriateness of use of coronary artery bypass graft surgery in New York State. JAMA 1993;269: 753-60

6. Bengston A, Herlitz J, Karlsson T, Brandrup-Wognsen G, Hjalmarson A. The appropriateness of performing coronary angiography and coronary artery revascularization in a Swedish population. JAMA 1994;271:1260-5 7. McGlynn EA, Naylor CD, Anderson GM, et al. Comparison of the appropriateness of coronary angiography and coronary artery bypass graft surgery between Canada and New York State. JAMA 1994;272:934-40. 8. Roos LL, Bond R, Naylor CD, Chassin MR, Morris AL. Coronary an giography and bypass surgery in Manitoba and the United States: a first comparison. Can J Cardiol 1994;10:49-56.

9. Rigter H, Meijler AP, McDonnell J, Scholma JK, Bernstein SJ. Indications for coronary revascularization: a Dutch perspective. Heart 1997;77: 211-8.

10. Meijler AP, Rigter H, Bernstein SJ, et al. The appropriateness of intention to treat decisions for invasive therapy in coronary artery disease in the Netherlands. Heart 1997;77:219-24.

11. Bernstein SJ, Brorsson B, Aberg T, Emanuelsson H, Brook RH, Werko L. Appropriateness of referral of coronary angiography patients in Sweden. Heart 1999;81:470-7.

12. Kravitz RL, Laouri M, Kahan JP, et al. Validity of criteria used for detecting underuse of coronary revascularization. JAMA 1995;274:632-8.

13. Kravitz RL, Laouri M. Measuring and averting underuse of necessary cardiac procedures: a summary of results and future directions. Jt Comm J Qual Improv 1997;23:268-76.

14. Laouri M, Kravitz RL, French WJ, et al. Underuse of coronary revascularization procedures: application of a clinical method. J Am Coll Cardiol 1997;29:891-7.

15. Carlisle DM, Leape LL, Bickel S, et al. Underuse and overuse of diagnostic testing for coronary artery disease in patients presenting with new-onset chest pain. Am J Med 1999;106:391-8.

16. Leape LL, Hilborne LH, Bell R, Kamberg C, Brook RH. Underuse of cardiac procedures: do women, ethnic minorities, and the uninsured fail to receive needed revascularization? Ann Intern Med 1999;130:183-92. 17. Ayanian JZ, Landrum MB, Normand S-LT, Guadagnoli E, McNeil BJ. Rating the appropriateness of coronary angiography — do practicing physicians agree with an expert panel and with each other? N Engl J Med 1998;338:1896-904.

18. Shekelle PG, Kahan JP, Bernstein SJ, Leape LL, Kamberg CJ, Park $\mathrm{RE}$. The reproducibility of a method to identify the overuse and underuse of medical procedures. N Engl J Med 1998;338:1888-95.

19. Hemingway H, Crook AM, Dawson JR, et al. Rating the appropriateness of coronary angiography, coronary angioplasty and coronary artery bypass grafting: the ACRE study. J Public Health Med 1999;21:421-9. 20. Parsonnet V, Dean D, Bernstein AD. A method of uniform stratification of risk for evaluating the results of surgery in acquired adult heart disease. Circulation 1989;79:Suppl I:I-3-I-12.

21. Hemingway H, Crook AM, Feder G, Dawson JR, Timmis A. Waiting for coronary angiography: is there a clinically ordered queue? Lancet 2000 ; 355:985-6. 
22. Bernstein SJ, Laouri M, Hilborne LH, et al. Coronary angiography: a literature review and ratings of appropriateness and necessity. Santa Monica, Calif:: RAND, 1992

23. Campeau L. Grading of angina pectoris. Circulation 1976;54:522-

24. Ringqvist I, Fisher LD, Mock M, et al. Prognostic value of angiographic indices of coronary artery disease from the Coronary Artery Surgery Study (CASS). J Clin Invest 1983;71:1854-66.

25. Banerjee S, Crook AM, Dawson JR, Timmis AD, Hemingway H. Magnitude and consequences of error in coronary angiography interpretation (the ACRE study). Am J Cardiol 2000;85:309-14.

26. The international statistical classification of diseases and related health problems, 10th rev.: ICD-10. Geneva: World Health Organization, 1992 27. Tunstall-Pedoe $H$, Kuulasmaak K, Amouyel P, Arveiler D, Rajakangas AM, Pajak A. Myocardial infarction and coronary deaths in the World Health Organization MONICA Project: registration procedures, event rates, and case-fatality rates in 38 populations from 21 countries in four continents. Circulation 1994:90:583-612.

28. SAS user's guide, version 6. Cary, N.C.: SAS Institute, 1990

29. Kosecoff J, Fink A, Brook RH, Chassin MR. The appropriateness of using a medical procedure: is information in the medical record valid? Med Care 1987;25:196-201.

30. Bell MR, Berger PB, Holmes DR Jr, Mullany CJ, Bailey KR, Gersh

BJ. Referral for coronary artery revascularization procedures after diagnostic coronary angiography: evidence for gender bias? J Am Coll Cardiol 1995; $25: 1650-5$.

31. Brook RH, Kosecoff JB, Park RE, Chassin MR, Winslow CM, Hampton JR. Diagnosis and treatment of coronary disease: comparison of doctors' attitudes in the USA and the UK. Lancet 1988;1:750-3.

32. Hux JE, Naylor CD. Are the marginal returns of coronary artery surgery smaller in high-rate areas? Lancet 1996;348:1202-7.

33. Eagle KA, Guyton RA, Davidoff R, et al. ACC/AHA guidelines for coronary artery bypass graft surgery: a report of the American College of Cardiology/American Heart Association Task Force on Practice Guidelines (Committee to Revise the 1991 Guidelines for Coronary Artery Bypass Graft Surgery). J Am Coll Cardiol 1999;34:1262-347.

34. Peters RJ, Bredee JJ. Indications for coronary revascularization: guidelines for the Netherlands. Heart 2000;83:3-4.

Copyright (C) 2001 Massachusetts Medical Society. 